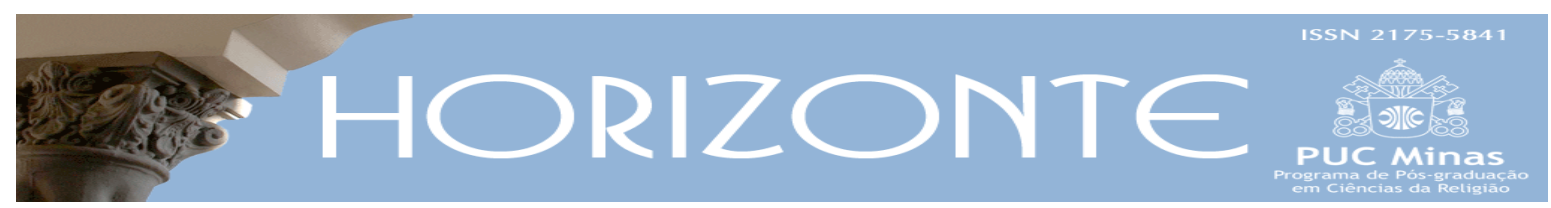

Temática Livre - Artigo Original

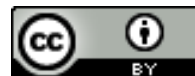

DOI - 10.5752/P.2175-5841.2018v16n50p845

\title{
Desconstrução e justiça: uma abertura frente ao outro
}

\section{Deconstruction and justice: one opening against the other}

\author{
Verónica Pilar Gomezjurado Zevallos*
}

\begin{abstract}
Resumo
O objetivo deste artigo é apresentar uma argumentação sobre a possibilidade de se pensar a justiça como uma experiência do impossível. Parte-se da distinção derridiana entre justiça e direito. Essa distinção trará algumas implicações no que tradicionalmente é entendido como ética. Partindo do jogo ou da différance marcada entre a presença/ausência, pretende-se estabelecer um ponto de diálogo entre Derrida e Levinas. O ponto de aproximação é a questão do terceiro (justiça) na relação do face a face. Nesse sentido, problematiza-se se a desconstrução pode ser adotada como um (im)possível modo filosófico que fundamente a compreensão da justiça. Este estudo se justifica pela necessidade sempre urgente de repensar as condições de possibilidade da ética, pensar não somente os limites impostos, mas explorar a estrutura que torna possível a ética: a justiça, a responsabilidade e a própria decisão no agir.
\end{abstract}

Palavras-chave: justiça; alteridade; desconstrução.

\begin{abstract}
The purpose of this article is to show an argumentation about the possibility of thinking justice as an experience of the impossible. Starting from the Derridian distinction between justice and rights. This distinction will bring some implications about what is traditionally understood by ethics. Starting from the game or the différance marked between presence/absence, it is intended to stablish a dialogue point between Derrida and Levinas. The approaching point is the question of the third (justice) in the relationship of the face to face. Thus, it will be problematized if the deconstruction can be adopted as an (im) possible philosophical way that can substantiate the comprehension of justice. This study is justified by the need always urgent to rethink the conditions of the ethics' possibility, to think again not only in the imposed limits, but explore the structure that makes the ethics possible: the justice, the responsibility and the own act on the decision.
\end{abstract}

Key words: justice; otherness; deconstruction.

\footnotetext{
Artigo recebido em 30 de setembro de 2017 e aprovado em 28 de agosto de 2018.

* Doutora em Filosofia pela Universidade do Vale do rio dos Sinos - UNISINOS. Professora da Universidade de Caxias do Sul. País de origem: Brasil. E-mail: vpgzeval@ucs.br
}

Horizonte, Belo Horizonte, v. 16, n. 50, p. 845-863, maio/ago. 2018 - ISSN 2175-5841 


\section{Introdução}

Escrever sobre Derrida é uma resposta à Derrida e, desde já, fazer justiça a sua escrita. Qualquer discurso sobre a desconstrução, no momento em que a própria desconstrução começa pela desestabilização de certezas, de uma forma ou outra, desemboca na problemática de justiça; de fazer justiça, de se fazer justiça. Os mais variados textos derridianos, desde, por exemplo, L'écriture et la différence ou Marges de la philosophie até os numerosos textos consagrados à Emmanuel Levinas, são discursos oblíquos que, ao abordar de ponta a ponta a relação com o outro, abordam, necessariamente, a questão da justiça. Desse modo, a desconstrução, talvez, proporcione neste momento uma outra forma de se pensar os problemas tradicionalmente propostos pela ética e, principalmente, abordar a questão do agir humano na atualidade. Ao assumir isso como pressuposto, no

percurso desta análise, pretende-se mostrar alguns traçados da desconstrução e a sua relação com a justiça, assim como apontar possíveis decorrências nas questões éticas da atualidade. A discussão a ser levantada é se há ou não uma dimensão ética na desconstrução, ou até que ponto as dimensões éticas tradicionais são ameaçadas pela desconstrução.

A desconstrução, por um lado, implica a exigência de uma justiça; por outro, tem a tarefa de ser uma memória histórica e interpretativa do que foi herdado sob o nome de justiça. Toda esta discussão e a estreita ligação entre alteridade e justiça se encontram desde já atravessadas pela própria desconstrução. Todavia, perante a responsabilidade diante da memória, serão abordados temas inseparáveis das relações éticas, como a questão do impossíveis. O impossível como condição de toda possibilidade, na relação responsável com o outro. A responsabilidade de construir um outro discurso sobre a responsabilidade e sobre a própria justiça é uma tarefa sempre a ser retomada. A responsabilidade consiste, talvez, em encontrar um modo de pensar que permita assumir esse conceito como um conceito ambíguo. A responsabilidade abre a possibilidade de uma decisão livre, por isso talvez impossível de tomar decisões a cada encontro, na abertura 
incondicional à singularidade, ao outro sempre outro, qualquer outro, aquele que não pode ser apreendido. Sendo assim, a desconstrução não leva apenas a denunciar limites conceituais ou teóricos, mas também fatos mais concretos e seus efeitos, resultantes de alguma determinação herdada da justiça.

\section{Entre a justiça e o direito}

Assume-se neste estudo a noção de justiça fora de qualquer conotação de categoria política ou jurídica, mas como o "conteúdo da própria humanidade, sem o qual a humanidade torna-se vazia" (SOUZA, 2010, p. 94), pressupondo que a ética nada mais é do que uma vontade de justiça para com o outro, qualquer outro. A justiça vai além de um conceito jurídico ou político, pois permite a transformação do próprio direito e da política. Uma abertura para a vinda do outro, sempre porvir, sem a qual não é possível a justiça. O porvir da justiça se dá na medida em que o acontecimento excede as regras e o cálculo; a justiça como uma experiência da alteridade radical permite o próprio acontecimento. Nesse sentido, a desconstrução passa a ser a própria justiça. Nas palavras de Duque-Estrada, o que a desconstrução promove é um

deslocamento de ênfase que, do plano da formulação de questões e respostas, problemas e soluções, passa a recair sobre o plano das aporias, das contradições, dos investimentos arbitrários, das denegações, enfim, dos fatores de complicação de toda ordem que fazem parte, e que, para a desconstrução, necessariamente fazem parte da formulação de toda questão e toda resposta, de todo problema e toda solução. (DUQUEESTRADA, 2004, p. 35-36, grifo do autor).

Ao se afirmar que a desconstrução é sempre uma tomada de decisão, uma abertura de fronteiras e ultrapassagem de limites, afirma-se, também, que ela admite certa traição dividida entre o ato inaugural de uma ação e a sua repetição. A desconstrução tem um duplo gesto, pois propõe e exige uma decisão e, ao mesmo tempo, ela denuncia aquilo que faz. Essa decisão somente se realiza no respeito à singularidade que se inscreve, à alteridade, ao outro. A decisão é tomada como uma exigência de justiça determinada sempre pelo outro. Desse modo, é possível se falar 
de justiça ao tentar desconstruir a própria ética? Ou, será possível que a desconstrução abra a possibilidade de justiça?

Em Force de loi (1994), Derrida reivindica a distinção, tão antiga quanto emblemática, entre justiça e direito (lei). Tal distinção é difícil e instável entre, por um lado, a justiça que é incalculável, infinita, heterogênea e rebelde às regras e, por outro, o exercício da justiça como direito ou como um sistema de prescrições regulamentadas e codificadas. A justiça é colocada como condição indesconstrutível da desconstrução. Essa distinção não deixará de ter alguns efeitos no modo como tradicionalmente é entendida a ética. Esse pensamento terá como consequência a intervenção direta na utilização dos conceitos da metafísica tradicional como responsabilidade, justiça, direito (lei), decisão e dever. A justiça não pode ser reduzida a um conceito jurídico ou simplesmente a uma ideia que resolve as expectativas da ação humana.

Derrida, ao traduzir a expressão idiomática to enforce the law por aplicar a lei, argumenta que tal tradução perde a alusão literal da força autorizada que justifica a aplicabilidade de uma lei. A aplicabilidade é uma força implicada no conceito de justiça enquanto direito. A força da lei, por um lado, e a violência da sua aplicabilidade, por outro, são colocadas em questão. É possível que a força na aplicabilidade da lei seja justa? Ou, há alguma força que não seja violenta? Por exemplo, tanto no francês quanto no inglês, a apalavra alemã Gewalt é traduzida, frequentemente, por violência. Contudo, segundo Derrida, tal tradução é totalmente injusta, portanto, totalmente violenta. A palavra Gewalt significa também no alemão “poder legítimo, autoridade, força pública. Gesetzgebende Gewalt é poder legislativo, geistliche Gewalt é poder espiritual da Igreja, Staatsgewalt é a autoridade ou o poder do Estado. Gewalt é, portanto, ao mesmo tempo a violência e o poder legítimo, a autoridade justificada.”1 (DERRIDA, 1994,

\footnotetext{
1 “Pouvoir légitime, autorité, force publique. Gesetzgebende Gewalt, c'est le pouvoir législatif, geistliche Gewalt, c'est le pouvoir spirituel de l'Église, Staatsgewalt, c'est l'autorité ou le pouvoir d'État. Gewalt, c'est donc à la fois la violence et le pouvoir légitime, l'autorité justifiée." [Tradução nossa].
}

Horizonte, Belo Horizonte, v. 16, n. 50, p. 845-863, maio/ago. 2018 - ISSN 2175-5841 
p. 19). Nesse sentido, é possível distinguir entre a força de lei de um poder legítimo e a violência pretensamente originária que precisou instaurar essa autoridade?

Procurando uma resposta para a questão de como diferenciar, por um lado, a força que pode ser justa ou julgada legítima e, por outro, a violência, que se julga sempre injusta, Derrida retoma de Montaigne e Pascal aquilo que ambos denominaram de "fundamento místico da autoridade". As conclusões de Derrida coincidem com as observações de Montaigne e de Pascal: “As leis não são justas enquanto leis. Não obedecemos a elas porque são justas, mas porque têm autoridade [...] a autoridade das leis repousa apenas no crédito que lhes concedemos. Nelas acreditamos, eis o único fundamento.”2 (DERRIDA, 1994, p. 30). Segundo Derrida, a crítica pascalina, em seu princípio, remete ao pecado original e à corrupção das leis naturais, "nossa justiça [se anula] diante da justiça divina."3 (PASCAL apud DERRIDA, 1994, p. 31).

Para além da explicação proposta por Pascal e Montaigne sobre o "fundamento místico de autoridade", Derrida assinala que a justiça - no sentido do direito - não estaria simplesmente a serviço de uma força ou de um poder social existente antes ou fora dela, para a qual ela (a justiça) deveria se submeter ou ajustar. A clara distinção feita por Derrida entre direito e justiça se fundamenta numa justiça para além ou fora do direito, uma vez que a origem da autoridade, a fundação ou o fundamento, e a instauração da lei se apoiam sobre elas mesmas, “elas mesmas são uma violência sem fundamento".4 (DERRIDA, 1994, p. 34). A autoridade, o fundamento e a instauração da lei excedem a oposição do fundado e não fundado.

$\mathrm{Na}$ resposta endereçada sempre ao outro, há uma grande distinção entre o direito e a justiça. No pensamento derridiano, o direito não é a justiça: o direito “é o elemento do cálculo, é justo que haja um direito, mas a justiça é incalculável, ela

\footnotetext{
2 “Les lois ne sont pas justes en tant que lois. On ne leur obéit pas parce qu'elles sont justes mais patce qu'elles ont de l'autorité [...] L'autorité des lois ne repose que sur le crédit qu'on leur fait. On y croit, c'est là leur seul fondement. " [Tradução nossa].

3 "Notre justice [s'anéantit] devant la justice divine. " [Tradução nossa].

4 "Elles sont elles-mêmes une violence sans fondement." [Tradução nossa].
} 
exige que se calcule o incalculável”.5 (DERRIDA, 1994, p. 38). Nessa estrutura descrita por Derrida, o direito enquanto fundado, ou seja, construído sobre camadas textuais interpretáveis e transformáveis, é desconstruível. Já a justiça não é desconstruível. O filósofo tenta mostrar que a justiça é irredutível ao direito; entretanto, “a justiça exige, para ser concreta e efetiva, encarnar-se num direito, numa legislação”. 6 (DERRIDA, 2005, p. 72). De forma natural, não há nenhum modo de direito que possa ser adequado à justiça, não existe correspondência direta ou indiretamente do direito à justiça. Por esse motivo, sempre houve a possibilidade de, na história do direito, acontecerem mudanças e transformações, como a Declaração Universal dos Direitos Humanos. Essas mudanças e transformações no direito foram de certa forma possíveis porque a própria justiça é infinita, incalculável. A relação ética não pode ser um colocar em prática certas normas. Há, desde já, uma primeira violência7 na instauração das leis, já que elas não preveem a singularidade do outro. A norma, a lei e o direito tratam o outro como um outro universal, idêntico, sem respeitar a diferença sempre singular do outro.

O pensamento da desconstrução, segundo Derrida, é o pensamento da justiça, "a desconstrução é a justiça"8 (1994, p. 35); e quem solicita essa força da desconstrução e da justiça é o outro. A justiça é a autoridade do outro que dita a lei e abre à responsabilidade, ou seja, o outro é quem faz responder e falar na sua direção. O respeito à singularidade e à alteridade do outro leva, sempre, de forma contínua e inadequada, à tentativa de ser justo com o outro (ou consigo mesmo como outro). Derrida refere que, no pensamento ocidental, existem discursos

\footnotetext{
5 “Est l'élément du calcul, e til est juste qu'il y ait du droit, mais la justice est incalculable, elle exige qu'on calcule avec de l'incalculable." [Tradução nossa].

6 “La justice exige, pour être concrète et effective, de s'incarner dans un droit, dans une législation."[Tradução nossa].

${ }^{7}$ Lembra-se aqui a distinção feita por Derrida entre violência pura e não-violência pura: "Impliquée par le discours de Totalité et infini, permettant seule de laisser être les autres dans leur vérité, libérant le dialogue et le face à face, la pensée de l'être est donc aussi proche que possible de la non-violence. Nous ne la disons pas non-violence pure. Comme la violence pure la non-violence pure est un concept contradictoire. Contradictoire au-delà de ce que Levinas appelle 'logique formelle'. La violence pure, rapport entre des êtres sans visage, n'est pas encore violence, est non-violence pure. Et réciproquement: la non-violence pure, non-rapport du même à l'autre (au sens où l'entend Levinas) est violence pure. Seul un visage peut arrêter la violence mais d'abord parce que seul il peut la provoquer. Levinas le dit fort bien: 'La violence ne peut viser qu'un visage' (TI). Aussi, sans la pensée de l'être que ouvre le visage, il n'y aurait que non-violence ou violence pures. La pensée de l'être n'est donc jamais, dans son dévoilement, étrangère à une certaine violence." (DERRIDA, J. L'écriture et la différence. Paris: Éditions du Seuil, 1967 p. 217-218).

8 "La déconstruction est la justice." [Tradução nossa].
}

Horizonte, Belo Horizonte, v. 16, n. 50, p. 845-863, maio/ago. 2018 - ISSN 2175-5841 
metafísicos sobre a justiça, sobre a liberdade, etc.; entretanto, há talvez um modo de pensar a justiça que não seja nem metafísico nem não metafísico. Justifica-se essa afirmação uma vez que, para o autor, não há conceitos que sejam por si mesmos metafísicos ou não metafísicos. ${ }^{9}$

Percorrendo alguns textos de Heidegger, Aristóteles e Nietzsche sobre a justiça, Derrida ensina que o termo não se reduz à representação jurídica dada a ele.10 A justiça é algo interior à justiça, motivo pelo qual não é redutível, não é calculável. Com a palavra justiça Derrida refere-se à relação que respeita a alteridade do outro e responde para o outro, a partir do fato de pensar que o outro é outro. É preciso prestar atenção no outro não como algo inefável. Nesse pensamento da justiça com relação à alteridade do outro e contrariamente ao direito, é preciso levar em conta o cálculo para se pensar o incalculável. Em oposição ao direito, a justiça calcula com o incalculável que é o outro.

A desconstrução implica por um lado o sentido de uma responsabilidade sem limites - incalculável; a exigência de uma justiça infinita como tarefa de ser uma memória histórica e interpretativa do que foi herdado sob o nome de justiça, ou seja, os limites dos conceitos de justiça, direito, seus valores, normas e prescrições impostas sedimentadas ao longo da História. Por outro lado, a responsabilidade da desconstrução frente ao próprio conceito de responsabilidade, que regula a justiça e a justeza ${ }^{11}$ da conduta e do exercício ético e político.

A desconstrução já está empenhada, comprometida com essa exigência de justiça infinita [...] É preciso ser justo com a justiça, e a primeira justiça a fazer-lhe é ouvi-la, tentar compreender de onde ela vem, o que ela quer de nós, sabendo que ela o faz através de idiomas singulares (Díke, Jus,

\footnotetext{
${ }^{9}$ Neste momento é possível realizar um distanciamento do pensamento de Derrida com Levinas. Derrida realiza uma forte crítica à pretendida "superação da metafísica"; embora Levinas ressignifique o conceito de metafísica, observa-se que não é possível simplesmente sair da metafísica, é dentro da própria metafísica que se pode assinalar os limites conceituais utilizados nos discursos.

10 "Non pas pour la justice calculable et distributive. Non pas pour le droit, pour le calcul de la restitution, l'économie de la vengeance ou du châtiment [...] il faut encore penser la possibilité d'un pas au-delà du refoulement ; il y a un au-delà de l'économie du refoulement dont la loi le pousse à déborder de lui-même au cours d'une histoire [...]. Non pas pour l'égalité calculable, donc, pour la comptabilité ou l'imputabilité symétrisante et synchronique des sujets ou des objets, non pas pour un rendre justice qui se limiterait à sanctionner, à restituer et à faire droit, mais pour la justice comme incalculabilité du don et singularité de l'ex-position an-économique à autrui. 'La relation avec autrui - c'est-à-dire la justice '." (DERRIDA, 1993. p. 48).

${ }^{11} \mathrm{O}$ sentido de justeza é o "de l'adéquation entre ce qui est et ce qui est dit ou pensée, entre ce qui est compris, voire entre ce qui est pensé et dit ou entendu". (DERRIDA, 1994, p. 15-16).
}

Horizonte, Belo Horizonte, v. 16, n. 50, p. 845-863, maio/ago. 2018 - ISSN 2175-5841 
justitia, justice, Gerechtigkeit). É preciso também saber que a justiça se endereça sempre a singularidades, à singularidade do outro, apesar ou mesmo em razão de sua pretensão à universalidade. ${ }^{12}$ (DERRIDA, 1994, p. 44 , grifos do autor).

A desconstrução não leva apenas a denunciar limites conceituais ou teóricos, mas também a fatos mais concretos e a seus efeitos, resultantes de alguma determinação herdada da justiça. Todavia, a responsabilidade diante da memória, como entende Derrida, "é uma responsabilidade diante do próprio conceito de responsabilidade que regula a justiça e a justeza de nossos comportamentos, de nossas decisões teóricas, práticas, ético-políticas”. ${ }^{13}$ (DERRIDA, 1994, p. 45). Tudo seria bem mais simples se existisse uma verdadeira distinção entre o direito e a justiça ou, talvez, uma oposição logicamente regulada, afirma Derrida (1994). Entretanto, o direito é exercido sempre em nome da justiça, e a justiça exige ser estabelecida num direito colocado em ação.

O tema da justiça se apresenta não somente no encontro entre a desconstrução e a possibilidade de justiça, mas também trata da experiência da aporia, da invenção, do talvez, da justiça impossível. A estrutura aporética estará ligada à temporalidade e à impossibilidade de presentificação do presente. No pensamento derridiano, a aporia não é considerada um obstáculo para o pensamento, contrariamente, será condição de possibilidade do pensamento. Questões em torno da desconstrução, do direito e da justiça requerem a experiência da aporia. Entretanto, a expressão "experiência da aporia" apresenta um paradoxo. Tal paradoxo radica no sentido contraditório, ou oposto em um certo sentido, das palavras experiência e aporia. Por um lado, experiência significa uma travessia e encontra sua passagem sendo, portanto, possível; já a aporia, em certo sentido, assinala um não-passo, um não-caminho, uma ausência de saída. Desse modo, não

\footnotetext{
12 "La déconstruction est déjà gagée, engagée par cette exigence de justice infinie [...] II faut être juste avec la justice, et la première justice à lui rendre, c'est de l'entendre, d'essayer de comprendre d'où elle vient, ce qu'elle veut de nous, sachant qu'elle le fait à travers des idiomes singuliers (Díkē, Jus, justitia, justice, Gerechtigkeit, pour nous limiter à des idiomes européens qu'il serait peut-être aussi nécessaire de délimiter vers au à partir d'autres: nous reviendrons là-dessus). Il faut savoir aussi que cette justice s'adresse toutjours à des singularités, à la singularité de l'autre, malgré ou en raison même de sa prétention à l'universalité." [Tradução nossa].

13 "Est une responsabilité devant le concept même de responsabilité qui règle la justice et la justesse de nos comportaments, de nos décisions théoriques, pratiques, éthico-politiques." [Tradução nossa].
}

Horizonte, Belo Horizonte, v. 16, n. 50, p. 845-863, maio/ago. 2018 - ISSN 2175-5841 
poderia se dar a experiência da aporia, pois não se pode ter experiência da não experiência.

Tal experiência do indecidível é a maior antípoda da complacência, é a vigília permanente de pensamento que ocorre como a interrupção do consenso. A desconstrução é uma "ciência" do indecidível [...] isto é, a tentativa implacável e rigorosa para determinar, através de um ato escrupuloso de uma leitura atenta, as figuras de indecisão (por exemplo, Geist, phármakon, suplemento) no contexto ilimitado do que podemos chamar (rature sous) "experiência". ${ }^{14}$ (CRITCHLEY, 1999, p. 261).

Esse ponto de vista, no pensamento derridiano, é o caso da justiça: a justiça é a experiência daquilo que não se pode experimentar. Derrida anuncia que, por impossível que pareça, não há justiça sem a experiência da aporia: "Uma vontade, um desejo, uma exigência de justiça cuja estrutura, não fosse uma experiência da aporia, não teria nenhuma chance de ser o que ela é, a saber, um justo chamado à justiça.15 (DERRIDA, 1994, p. 38). A experiência da aporia provoca um modo de pensar na possibilidade do que ainda permanece impensado, na verdade, do impossível. A justiça não pode ser reduzida a um conceito jurídico ou simplesmente a uma ideia que resolve as expectativas da ação humana. A justiça é a possibilidade de transformação. Contudo, a justiça nunca pode ser plenamente experimentada, pois jamais se encontra no presente, nesta ou naquela ação política. A justiça é irredutível a qualquer cálculo e acontece na experiência, sem jamais tornar-se presente. Nesse sentido, a justiça seria a experiência daquilo que não se pode experimentar. Embora a justiça se instaure no direito posto em ação, ela chama à responsabilidade do imprevisível e sempre outro. Para além do pensamento regulador em sua forma clássica, a ideia - caso seja uma ideia - da justiça como um porvir ou como acontecimento não é possível de ser apreendida. Essa ideia nunca se apresentará na forma da presença única e total.

\footnotetext{
14 "Such an experience of undecidability is at the very antipodes of complacency, it is the perpetual wakefulness of thinking taking place as the interruption of consensus. Deconstruction is a 'science' of the undecidable [...] that is, the relentless and rigorous attempt to determine, through a scrupulous act of close reading, the figures of undecidability (e.g. Geist, phármakon, supplement) in the limitless context of what we can call (sous rature) 'experience'." [Tradução nossa].

15 “II n’y pas de justice sans cette experiènce, tout impossíble qu'elle est, de l'aporie. La justice est une experiénce de l'impossible. Une volonté, um désir, une exigence de justice dont la structure ne serait pas une experiénce de l'aporie n'aurait aucune chance d'être ce qu'elle est, à savoir juste appel de la justice." [Tradução nossa].
}

Horizonte, Belo Horizonte, v. 16, n. 50, p. 845-863, maio/ago. 2018 - ISSN 2175-5841 


\section{Derrida herdeiro de Levinas}

A desconstrução, no entender de Derrida, mantém uma relação um tanto complicada com a Filosofia. Essa relação é, ao mesmo tempo, de pertença e de herança, assim como de ruptura e deslocamento. Possuir uma herança é um fato que ninguém pode negar. Todos somos herdeiros e sempre será recebido algo já existente, algo já dado. Com isso, não se pretende dizer "que temos ou que recebemos isto ou aquilo, que tal herança nos enriquece um dia com isto ou aquilo, mas que o ser disso que somos é primeiramente herança, quer o queiramos e o saibamos ou não". ${ }^{16}$ (DERRIDA, 1993, p. 94). A herança chama para uma reafirmação e uma transformação tão radical quanto possível.

A escrita de Derrida demonstra uma forte afinidade com a obra de Emmanuel Levinas, cujo trabalho se destaca como uma tentativa sem precedentes na filosofia moderna de articular o que significa fazer justiça para o outro. [...] Derrida alegou que ele está preparado para concordar com tudo que Levinas disse e que as diferenças entre eles são biográficas e não de natureza filosófica.17 (BIESTA, 2009, p. 28).

Derrida, em Adeus a Emmanuel Levinas, pronuncia palavras de boasvindas: "deixando-se assim receber, mas também ouvir e interpretar, escutar e interrogar”. A desconstrução derridiana possui forte influência do pensamento de Levinas, especialmente no pensamento ético. A questão do outro, do absolutamente outro (tout autre) ${ }^{18}$, é o tema central de proximidade, de herança e, talvez, de afastamento, nos escritos de Derrida a partir da década dos anos 80, com

\footnotetext{
16 "Que nous avons ou que nous recevons ceci ou cela, que tel héritage nous enrichit un jour de ceci ou de cela, mais que l'être de ce que nous sommes est d'abord héritage, que nous le voulions et le sachions ou non." [Tradução nossa].

17 "Derrida's writing demonstrates a strong affinity to the work of Emmanuel Levinas, whose work stands out as an unprecedented attempt in modern philosophy to articulate what it means to do justice to the other. [...] Derrida has contended that he is prepared to agree with everything Levinas has said and that the differences between them are of a biographical and not of a philosophical nature." [Tradução nossa].

${ }^{18}$ Toma-se aqui a nota dos tradutores de Fe y Saber explicando o jogo de palavras do tout autre est tout autre: "cualquier/radicalmente otro es cualquier/radicalmente otro - esta expresión, en principio, puede parecer tautológica si no se le presta atención a la homonimia de tout (adjetivo pronominal indefinido que se podría reemplazar por 'cualquier')... tout (adverbio de cantidad equivalente a 'totalmente', 'absolutamente', 'radicalmente', 'infinitamente')... Si el primer tout es un adjetivo pronominal indefinido, el primer autre será sustantivo y, probablemente, el segundo tout será un adverbio de cantidad que afectaría a un adjetivo o atributo. Con ello escaparíamos a la aparente tautología. No obstante, la posibilidad de la tautología persiste si el segundo miembro de la frase permaneciera análogo al primero: "I'autre est l'autre, l'altérité de l'autre est l'altérité de l'autre". En todo caso, siempre nos encontraríamos ante una proposición hetero-tautológica." (DERRIDA, 2006, p. 81-82. [Nota dos tradutores] ).
}

Horizonte, Belo Horizonte, v. 16, n. 50, p. 845-863, maio/ago. 2018 - ISSN 2175-5841 
Levinas. ${ }^{19} \mathrm{O}$ outro que é absolutamente outro (a justiça) é um outro em différance? Por outro lado, a ideia do absolutamente outro (tout autre) do outro, na ética levinasiana, é, por princípio, inacessível. Essa ideia é colocada em questão no pensamento derridiano. $\mathrm{O}$ absolutamente outro tem referência a uma outra pessoa à luz da transcendência divina. Em Derrida, o outro é um qualquer outro. Este outro pode abranger, inclusive, muito mais que apenas seres humanos (os animais, por exemplo). Derrida denuncia que, quando Levinas se interroga sobre o outro do outro [ou seja, o terceiro], e que faz surgir a justiça, este não é somente um “semelhante”. O não-semelhante permanece um humano e não um outro qualquer, diferente do homem. Na questão levantada, percebe-se que Derrida vai além do pensamento de Levinas na sua vontade de justiça do absolutamente outro (Levinas) ao absolutamente qualquer outro (Derrida). Partindo da proposta derridiana da différance é possível marcar um afastamento do absolutamente outro levinasiano. Parece que, em Totalidade e Infinito, o absolutamente outro (tout autre) marcaria só um dos sentidos do verbo différer (diferir), a saber, o de diferente/dessemelhante, já o (tout autre) da desconstrução seria, talvez, o outro em différance. Esse absolutamente ${ }^{20}$ outro em différance (outro irredutível) se encontra simultaneamente em movimento entre o diferente/dessemelhante e o diferente/prorrogado. Dessa maneira, se estabelece uma relação de impossibilidades no encontro com o outro. A partir dessa análise, afirma-se que a justiça se encontra sempre em différance, num jogo entre aquilo que se apresenta e aquilo que, como próprio da sua estrutura, está ausente.

A herança levinasiana na desconstrução será o marco decisivo de abertura às questões éticas impossíveis assumidas por Derrida. Como a herança não é simplesmente algo que se apresenta para ser usufruída, ela sempre será uma tarefa

\footnotetext{
19 “Chaque fois que je lis ou relis Emmanuel Lévinas, je suis ébloui de gratitude et d'admiration, ébloui par cette nécessité, qui n’est pas une contrainte mais une force très douce qui oblige et qui oblige non pas à courber autrement l'espace de la pensée dans son respect de l'autre, mais à se rendre à cette autre courbure hétéronomique qui nous rapporte au tout autre (c'est-à-dire à la justice, dit-il, quelque part, dans une puissante et formidable ellipse: le rapport à l'autre, dit-il, c'est-à-dire la justice), selon la loi que appelle donc à se rendre à l'autre préséance infinie du tout autre." (DERRIDA, 1997, p. 22).

${ }^{20} \mathrm{Na}$ proposta desenvolvida ao longo deste trabalho: de uma ética do impossível, assume-se o absolutamente outro como um movimento da différance; o outro é ao mesmo tempo diferente/dessemelhante e diferente/prorrogado, permitindo que a abertura ao outro seja sempre uma relação impossível.
}

Horizonte, Belo Horizonte, v. 16, n. 50, p. 845-863, maio/ago. 2018 - ISSN 2175-5841 
que exige recepção crítica e ativa. Aquilo que se herda não é, em momento algum, uma propriedade, um bem próprio e determinado. A herança é sempre problemática e demanda certa violência para sua afirmação: é um filtro crítico e transformador. A problemática da herança parte, primeiramente, da experiência de herança, e essa experiência começa por se apropriar daquilo que vem "antes de nós". Apropriar-se de um passado que sempre permanece inapropriável, quer se trate de uma língua, de uma cultura, quer se trate de um texto, um discurso, um pensamento filosófico. Uma abertura de tudo aquilo que foi transmitido, num contexto diferente, a outras "leituras", diálogos, filtrações, transformações, desconstruções.

A justiça será sempre inventiva à vinda do outro. Não se trata aqui da invenção do possível nem da sua oposição, mas de reinventar sempre a própria invenção, dando lugar à vinda do outro sempre inesperado e imprevisível. Defendese aqui a noção de justiça como um indecidível radicalmente desligado do direito enquanto lei. Esse pensamento permite a passagem para uma noção de justiça como constitutiva da relação ética entre o face-a-face, aquilo que se apresenta e, ao mesmo tempo, imprevisível na singularidade do outro, aquilo que está ausente e jamais pode se apresentar no presente. Uma relação será sempre descontínua, na qual o eu se oferece a um encontro sempre singular. Desse modo entende-se a justiça como algo que não se apresenta, mas acontece; uma resposta a um chamado por justiça. A implicação ética que se estabelece no jogo entre presença e ausência, na relação com a justiça, propõe uma abertura inventiva, impossível e imprevisível, a cada singular situação, sem qualquer pretensão de capturar o outro numa simples normatividade.

Ao se falar em responsabilidade, é preciso ir além de um entendimento que pretenda simplesmente regulamentar ou normatizar as relações do ser humano com o outro. Este outro pode abranger, inclusive, muito mais que apenas seres humanos (os animais, por exemplo). A ideia de responsabilidade como impossível ou uma ética do impossível pode vir a acontecer, talvez, num pensamento sem 
garantia de resposta. Admitir que a responsabilidade está arraigada na impossibilidade do calculável é admitir que o outro está sempre porvir e, em circunstância alguma, poderá ser apreendido. Assumir este pensamento abre a possibilidade de uma constante renovação ao se tratar das relações do ser humano com o outro. Uma relação imprevisível, não programável, mas que exige uma tomada de decisão. Para tal decisão é preciso levar em consideração tudo aquilo que não pode se apresentar no próprio encontro, na própria relação, o ausente. É preciso levar em conta a alternância necessária entre aquilo que se apresenta e seu próprio constituinte que é a ausência. Como uma restância do resto que impede um fechamento metódico, mas que não se presentifica, pois permanece ausente na presença.

Abordagens sobre ética, responsabilidade e justiça, frequentemente são pensadas numa ação frente ao outro, na presença do outro. Faz-se necessário admitir que toda presença, inevitavelmente, está perpassada por uma ausência, sem que seja simplesmente seu oposto, mas sim seu constitutivo. Essa outra leitura da responsabilidade e, por consequência, da justiça, deriva da força da différance no afastamento ou retardo, constatando, a partir da différance, uma relação que, necessariamente, acontece na diferença e, portanto, em relação com a alteridade. Não como simples oposição entre dois elementos distintos, mas uma relação entre dois singulares que nunca se mostram em si mesmos e que, por razões estruturais, sempre escapa. Uma relação de abertura diante do outro impossível de ser apreendido. Uma relação sem relação, uma relação impossível. A abertura ao encontro do outro acontece no limiar da frágil relação entre o que se apresenta e o que está ausente, no jogo entre a presença/ausência do outro. Uma relação em différance na qual a singularidade do sujeito não coincide com a individualidade de si, pois a singularidade se desloca, se afasta, é postergada para responder ao chamado do outro. Ela se oculta (ausência de si) como rastro para ir ao encontro do outro na sua imprevisibilidade, um outro dentro de um a silencioso, em différance, permanecendo sempre secreto e discreto. Esse $\boldsymbol{a}$ silencioso conduz tanto a uma atividade, pois sempre está em movimento, quanto a uma passividade; o jogo é 
independente de qualquer vontade. A différance da alteridade não mais é pensada a partir do logos racional, mas a partir do impossível e incalculável. Assim, se coloca em questão as próprias condições de possibilidade do que é possível. $\mathrm{O}$ eu em différance se entrega à singularidade do outro, que vem antes de todo presente, pois vem do porvir e como porvir, a vinda mesma do acontecimento. Essa condição da indesconstruível justiça da desconstrução permanece e deve permanecer em desconstrução.

\section{A justiça: 0 terceiro e a différance}

A entrada do terceiro é a comparação dos incomparáveis - a tematização do Mesmo, a partir da relação com o outro, da proximidade e da imediatez do dizer anterior aos problemas -, enquanto que a identificação do conhecer prende o todo outro. Contudo, Levinas adverte que a entrada do terceiro não é um fato empírico e que a responsabilidade não é obrigada ao cálculo Conforme afirma Haddock-Lobo,

O terceiro, ainda que descrito por Levinas de acordo com a cronologia de uma genealogia familiar (eu-pai, tu-mãe, ele-filho), já participa desde sempre da relação dual. Mais ainda, é sua presença quase fantomática que se manifesta na epifania dos olhos do outro, que conduz a própria relação dual erótica. É a eterna presença da terceira parte, alteridade absoluta que possibilita a ética mesma, pois, por ser vista desde o primeiro encontro de olhares entre o mesmo e o outro, ela acaba por frustrar a relação erótica, ao evidenciar a impossibilidade de reconciliação eterna entre as suas almas que desejavam tornar-se uma só: no momento em que se pensava ocorrer a união. (HADDOCK-LOBO, 2004, p. 175).

Nessa relação dual, o terceiro participa já desde sempre e sua presença é quase que fantomática, se apresenta na sua ausência frente ao rosto do outro que é infinito. Essa relação dual acontece entre a ausência/presença do terceiro. Por um lado, Levinas afirma, em De Deus que vem à ideia (2002, p. 119), que "o termo 'justiça' aplica-se muito mais à relação com o terceiro do que à relação com outrem. Mas, na realidade, a relação com outrem nunca é só a relação com outrem: desde já o terceiro está representado em outrem; na própria aparição do outro o terceiro já está a me olhar. Isto faz com que a relação entre responsabilidade para com outrem e a justiça seja extremamente estreita” e, em Adieu à Emmanuel Levinas (1997, p. 
66), Derrida afirma que "O terceiro não espera, sua eleidade conclama desde a epifania do rosto face-a-face. Porque a ausência do terceiro ameaçaria de violência a pureza ética no imediatismo absoluto do face-a-face como o único." ${ }^{21}$ Derrida afirma que Levinas não o diz desta maneira mas que, ao fazê-lo, Levinas não leva em conta a violência potencial que desencadeia a experiência do próximo na sua singularidade. "O terceiro protegeria pois contra a vertigem da violência propriamente dita.”22 (DERRIDA, 1997, p. 66). Então, é possível afirmar que o terceiro, o qual se encontra desde já na relação - mas está ausente enquanto presente - e a necessidade de justiça se faz presente, então a justiça acontece no jogo entre presença/ausência do outro ou do próximo. Para que uma decisão seja justa e responsável,

é preciso que, em seu momento próprio, se houver um, ela seja ao mesmo tempo regrada e sem regra, conservadora da lei e suficientemente destruidora ou suspensiva da lei para dever em cada caso reinventá-la, rejustificá-la, reinventa-la ao menos na re-afirmação e na confirmação nova e livre de seu princípio. Cada caso é um caso, cada decisão é diferente e requer uma interpretação absolutamente única, que nenhuma regra existente ou codificada não pode nem deve absolutamente garantir. ${ }^{23}$ (DERRIDA, 1994, p. 51).

O questionamento sobre a ausência mantém o outro inacessível como condição de im/possibilidade da relação com o outro ou uma relação sem relação, para além do presente ou da mera aparência. Sempre questões permanecem em aberto, e é preciso que isso aconteça para não fixar nenhum pensamento; contudo, partindo da análise realizada nesta investigação, é possível afirmar que a responsabilidade, a justiça e a própria ética são impossíveis, encontram-se em différance, num jogo de presença/ausência. Todos esses temas relacionados à ética se estabelecem com rastro que não as coloca como presença, mas como ausência. Ausente porque imprevisível, não programável, incalculável e indecidível. O

\footnotetext{
21 “Le tiers n'attend pás, son illéité appelle dès l'épiphanie du visage dans le face-à-face. Car l'absence du tiers menacerait de violence la pureté de l'éthique dans l'immédiateté absolue du face-à-face avec l'unique." [Tradução nossa].

22 "Le tiers protégerait donc contre le vertige de la violence éthique Même." [Tradução nossa].

23 “Il faut que dans son momente propre, s'il y en a un, elle soit à la fois réglée et sans règle, conservatrice de la loi et assez destructrice ou suspensive de la loi pour devoir à chaque cas la réinventer, la re-justifier, la réinventer au moins dans la réaffirmation et la confirmation nouvelle et libre de son principe. Chaque cas est autre, chaque décision est différente et requiert une interprétation absolument unique, qu'aucune règle existante et codée ne peut ni ne doit absolument garantir." [Tradução nossa].
}

Horizonte, Belo Horizonte, v. 16, n. 50, p. 845-863, maio/ago. 2018 - ISSN 2175-5841 
ausente exclui a norma, uma vez que não tem como saber qual a decisão responsável. A decisão responsável só acontece no acontecimento do encontro (face a face). Assim, em certo sentido, o terceiro é um certo ausente. O terceiro é ao mesmo tempo presente e ausente, o que coloca em questão o próprio saber, pois a decisão ética é um não-saber. O momento da decisão, o momento ético, independe do saber e supõe uma ruptura com a lógica clássica do cálculo. O outro, o absolutamente qualquer outro, não se deixa representar por isso, a justiça acontece na própria experiência, sem jamais tornar-se presente. A ausência do outro é precisamente sua presença como outro.

Na presença do outro, no frente a frente, o eu é modificado a cada instante e é a partir dessas mudanças e de como essas mudanças se articulam no pensamento que o agir acontece. Sendo assim, o agir ético não é um desdobrar de algo já dado ou algo preestabelecido, mas o resultado das modificações dadas no próprio encontro frente ao rosto do outro. Tais mudanças não podem ser previstas ou calculadas, elas acontecem somente a partir do encontro. A mudança não é uma ideia normativa a ser alcançada. Isso talvez nos leve a um pensamento tal que o agir ético, a escolha e a decisão são impossíveis de ser programadas, são imprevisíveis. Se a decisão pudesse ser programada (agir conforme normas e leis) o outro seria capturado a partir de um pensamento do eu. Não se poderia afirmar a inexistência de critérios para o acontecer da decisão, mas esses critérios não podem ser universais nem preestabelecidos. As minhas escolhas terão lugar a partir dos critérios que acontecem no encontro com o outro. Para tanto, se faz necessário uma abertura à vinda do outro, abertura para uma resposta à singularidade do outro. A abertura não é uma subordinação ao outro, mas um permitir e se permitir acolher. Acolher o outro na sua ausência é fazer justiça sem violência. Decidir sem agredir. Ter responsabilidade perante o outro, não como imposição ou à força, mas como abertura e acolhimento ao cada vez outro. Uma abertura, sempre inventiva para a experiência do impossível. Uma justiça sempre a ser inventada, a partir da singularidade do outro. 


\section{Considerações finais}

Fica claro que a desconstrução derridiana possui uma forte influência do pensamento levinasiano, especialmente no pensamento sobre as questões éticas. $\mathrm{O}$ outro, o "absolutamente" outro, é o tema central de proximidade, de herança, e, talvez, de afastamento, nos escritos de Derrida para Levinas. A ideia do absolutamente outro (tout autre) do outro, na ética levinasiana é, por princípio, inacessível. Essa ideia é colocada em questão no pensamento derridiano. O absolutamente outro levinasiano tem referência a uma outra pessoa à luz da transcendência divina. Em Derrida, o outro é um qualquer outro. Este outro pode abranger, inclusive, mais que apenas seres humanos (os animais, por exemplo). Derrida denuncia que, quando Levinas se interroga sobre o outro do outro [ou seja, o terceiro], e que faz surgir a justiça, este não é somente um "semelhante". O nãosemelhante permanece um humano e não um outro qualquer, diferente do homem. Na questão levantada, percebe-se que Derrida vai além do pensamento de Levinas na sua vontade de justiça do absolutamente outro (Levinas) ao absolutamente qualquer outro (Derrida). Partindo da proposta derridiana da différance, é possível marcar um "afastamento" do absolutamente outro levinasiano. O absolutamente outro tout autre marca só um dos sentidos do verbo différer (diferir), a saber, o de diferente/dessemelhante, já o (tout autre) da desconstrução é o outro em différance (outro irredutível), que se encontra simultaneamente em movimento entre o diferente/dessemelhante e o diferente/prorrogado. Dessa maneira, estabelece-se uma relação de impossibilidade no encontro com o outro. $\mathrm{O}$ acontecimento, a decisão e a própria justiça só têm lugar quando o impossível se fizer possível, quando vier do possível, cuja possibilitação prevalecer sobre o impossível.

Sob uma perspectiva do impossível, como condição de possibilidade do possível, é delineado um pensamento da ética como impossível. O impossível permite, possibilita a possibilidade de qualquer acontecimento, neste caso o da justiça. Derrida e Levinas possuem algumas divergências tanto no significado de 
justiça como no caráter de autoridade em torno do direito. No pensamento derridiano, o direito não é a justiça: o direito é calculável, mas a justiça é incalculável; ela exige que se calcule o incalculável. Embora a justiça se instaure no direito, posto em ação, ela chama à responsabilidade do imprevisível e sempre outro, para além do pensamento regulador em sua forma clássica. A partir dessa análise, afirma-se que a justiça se encontra sempre em différance, num jogo entre aquilo que se apresenta e aquilo que, como próprio da sua estrutura, está ausente. Já no pensamento levinasiano, a justiça é considerada a própria relação com o outro.

Torna-se urgente repensar as condições de possibilidade da ética. Pensar novamente não somente os limites impostos, mas explorar a estrutura que torna possível a ética: a justiça, a responsabilidade, a hospitalidade, o perdão, o dom, o segredo e a própria decisão. A desconstrução ética, especificamente das questões éticas abordadas na atualidade, propõe repensar o sistema de normas, regras da ética normativa ou a ética aplicada. Trata-se de uma problematização do que é entendido com o nome de ética e sua possibilidade. Uma reflexão que remonta para questões sobre os paradoxos e aporias constitutivos da própria ética, do reconhecimento do impossível como condição de possibilidade da ética. Desconstruir o conceito de responsabilidade se dá em nome da própria responsabilidade. Um apelo à responsabilidade para manter uma certa vigilância com relação ao próprio conceito de responsabilidade. No pensamento derridiano, esta responsabilidade é intangível, não pode ser inaugurada. Tal responsabilidade tem que ser doada, para além do direito e do jurídico, além da moral. Esse pensamento nos remete para uma responsabilidade que supõe sempre o risco do mal e da injustiça, para os quais não existem garantias calculáveis e absolutas. 


\section{REFERÊNCIAS}

BIESTA, Gert J. J. Deconstruction, justice, and the vocation of education: between event and invention. In: PETERS, Michel; BIESTA, Gert J. J. Derrida, deconstruction, and the politics of pedagogy. New York: Peter Lang Publishing, 2009. p. 14-37.

CRITCHLEY, Simon. The ethics of deconstruction: Derrida and Levinas. Edingurgh: Edingurgh University Press, 1999.

DERRIDA, J. Adieu à Emmanuel Lévinas. Paris: Galilée, 1997.

DERRIDA, J. Fe y saber. Tradução Paco Vidarte; Cristina de Peretti. Buenos Aires: Ediciones de la Flor, 2006.

DERRIDA, J. Force de loi. Le fondement mystique de l'autorité. Paris: Galilée, 1994.

DERRIDA, J. L'écriture et la différence. Paris: Éditions du Seuil, 1967.

DERRIDA, J. Spectres de Marx. Paris: Galilée, 1993.

DERRIDA, J. Sur parole: instantanés philosophiques. Paris: Éditions de l'Aube, 2005.

DERRIDA, Jacques; ROUDINESCO, Elisabeth. De que amanhã... diálogo. Rio de Janeiro: J. Zahar, 2004.

DUQUE-ESTRADA, Paulo César (Org.). Desconstrução e ética: ecos de Jacques Derrida. Rio de Janeiro: Ed. PUC-Rio, 2004.

HADDOCK-LOBO, Rafael. As muitos faces do outro em Levinas. In: DUQUE-ESTRADA, Paulo César (Org.). Desconstrução e ética: ecos de Jacques Derrida. Rio de Janeiro: Ed. PUC-Rio, 2004. p. 165-192.

LEVINAS, Emmanuel. De Deus que vem à idéia. Petrópolis: Vozes, 2002.

SOUZA, Ricardo Timm de. Justiça em seus termos: dignidade humana, dignidade do mundo. Rio de Janeiro: Lumen Juris, 2010. 